\title{
MULTIREGIONAL POPULATION PROJECTION
}

Andrei Rogers

Jacques Ledent

Population projections illuminate the impacts of current schedules of births, deaths and migration by drawing out the future consequences of the maintenance of present rates. Methods for developing population projertions for single regions are well known, and the mathematics of such exercises have been documented in countless articles, and more recently, in several texts (e.g., Keyfitz, 1968; Pollard, 1973). The mathematics of population projection for multiregional systems that experience internal migration, however, are less known, and it is only recently that concepts such as the multiregional life table have given them a methodological consistency with the conventional mechanics of single-region population projection.

This paper is an exposition of the mathematics of multiregional population projection. We begin by outlining the notion of a multiregional life table. Next, we show how the stationary regional populations of such a life table serve as inputs to numerical calculations carried out with the multiregiona1 versions of the discrete and continuous models of demographic growth [e.g., Leslie, 1945, and Sharpe and Lotka, 1911, respectively]. We then conclude with a brief consideration of some of the spatial consequences of zero population growth.

Although some mathematics is inevitable in a paper such as this, we have attempted to avoid as much of the mathematical apparatus as possible. Further details may be found in the text by Rogers (1975).

Finally, an important ingredient of effective strategies to understand and resolve complex problems of a mathematical nature is a powerful notational system. In extending the principal results of single-region population mathematics to multiregional population systems, we generalize conventional 
notation as set out, for example, in Keyfitz (1968); although we do not distinguish notationally between continuous and discrete functions. The regional dimension is introduced by means of two subscripts which refer to regtons of birth and residence. As in the single-region theory, the argument of a variable usually refers to age, and the right superscript, also enclosed in parentheses, refers to time. The Glossary below brings together most of the variables used in this paper. 


\section{GLOSSARY}

\section{Observed Population}

$$
\begin{aligned}
& \begin{aligned}
j^{(t)}(x)= & \text { Number of individuals aged } x \text { to } x+4 \text { years at last birthday } \\
& \text { in region } i \text { at time } t \text { who were born in region } j .
\end{aligned} \\
& F_{i}(x) \quad=\text { Annual rate of childbearing in region } i \text { among individuals }
\end{aligned}
$$

\section{Stationary (Life Table) Population}

$$
\begin{aligned}
& \begin{aligned}
j^{l}(\mathrm{x})= & \text { Number of individuals at exact age } x \text { in region } i \text { who were } \\
& \text { born in region } j .
\end{aligned} \\
& \begin{aligned}
q_{i}(x)= & \text { Probability of dying within the next } 5 \text { years for individuals } \\
& \text { in region } i \text { at exact age } x .
\end{aligned} \\
& \begin{aligned}
P_{i j}(x)= & \text { Probability of residing in region } j \text { at exact age } x+5 \text { for } \\
& \text { individuals in region } i \text { at exact age } x .
\end{aligned} \\
& \begin{aligned}
j^{p_{i}}(x)= & \text { Probability of residing in region } i \text { at exact age } x \text { for } \\
& \text { individuals born in region } j .
\end{aligned} \\
& s_{i j}(x)=\text { Proportion of } x-t o-(x+4) \text {-year old residents of region } i \\
& \text { alive and } x+5 \text { to } x+9 \text { years in region } j 5 \text { years later. } \\
& j_{i} \mathrm{~L}_{i}(x)=\text { Number of individuals aged } x \text { to } x+4 \text { years at last birthday }
\end{aligned}
$$

\section{Stable Population}

$\lambda=$ Stable 5 -year growth ratio.

$r \quad=$ Intrinsic rate of growth. 
$\mathrm{b}_{j}=$ Intrinsic birth rate in region $j$.

$\mathrm{d}_{j} \quad=$ Intrinsic death rate in region $j$.

$0_{j}=$ Incrinsic outmigration rate in region $j$.

$i_{j}=$ Intrinsic inmigration rate in region $j$.

$\mathrm{n}_{j} \quad=$ Intrinsic net migration rate in region $j$.

$\sigma_{j}(x)=$ Proportion of the total stable population in region $j$ that is $x-$ to- $(x+4)$-years old.

$(\%)_{j}=$ Proportion of the total multiregional stable population that is in region $j$.

$\mathrm{Y}_{j} \quad=$ stable equivalent of region $j$.

$Q_{j}=$ Number of births in the stable population of region $j$. 


\section{The Multiregional Life Table}

A multiregional life table exhibits the mortality and migration history of an artificial population, called a cohort, as it gradually decreases in size until all of its members have died. Normally it is assumed that the age-specific mortality and migration experience to which this cohort is exposed remains constant and that the cohort is undisturbed by emigration and immigration. Consequently, changes in the cohort's membership can only occur in the form of a decrease due to deaths.

The data set out in a multiregional life table originate from a set of probabilities of outmigrating and of dying within each interval of age, $p_{i j}(x)$ and $q_{i}(x)$, respective1y, where $\sum_{j=1}^{m} p_{i j}(x)+q_{i}(x)=1$. Life tables that deal with age intervals of a year are frequently referred to as complete life tables, whereas those using longer intervals are called abridged life tables. We, however, shall ignore this somewhat spurious distinction and for convenience will, without loss of generality, deal only with 5-year age intervals throughout.

Let the regional radix $\ell_{i}(0)$ denote the number of babies born at a given instant in time in the $i^{\text {th }}$ region of an m-region multiregional population system. Subjecting these regional cohorts to the age-specific mortality and mobility of an observed population, we may obtain $\ell_{i}(x)$, the expected number of individuals who survive to exact age $\mathrm{x}$ in region $i$. However, we need to keep track of where these survivors were born. Consequently, let us introduce an additional subscript on the left-hand side of the variable to designate the region of birth, such that $j_{i}(x)$ denotes the expected number of survivors alive in region $i$ at age $x$ who were born in region $j$.

Consider the $j_{i}(x+5)$ residents of region $i$ at age $x+5$ who were born in region $j$. They are survivors of the $\sum_{h=1}^{m} j^{l} h(x) j$-born individuals who at age 
$x$ resided in any one of the m regions $(h=1,2, \ldots, m)$. Denoting by $p_{h i}(x)$ the probability that an individual in region h at age $x$ will survive and be in region i 5 years 1 ater, we have the relationship:

$$
j^{\ell}(x+5)=j^{\ell}{ }_{1}(x) p_{1 i}(x)+j^{\ell}(x) p_{2 i}(x)+\ldots=\sum_{h=1}^{m} j^{\ell} h(x) p_{h i}(x) .
$$

It has beep estimated that the probability that a female at age 10 and residing in California in 1958 would be living in the rest of the United States 5 years later is 0.058749 , and the probability that a female resident of the rest of the United States at the same age in 1958 would still be living there in 1963 is 0.985997 . Thus the number of Calitornia-born life table survivors at age 15 in the rest of the United States is

$$
\begin{aligned}
1_{2}^{l_{2}(15)} & ={ }_{1}^{l_{1}(10) \mathrm{p}_{12}(10)+1_{1}{ }_{2}(10) \mathrm{p}_{22}(10)} \\
& =85,751(0.058749)+11,544(0.985997) \\
& =5,038+11,382 \\
& =16,420,
\end{aligned}
$$

a quantity that appears in the second row-first column position in the lower half of the array set out in Table 1 . The regional radices for that table were both arbitrarily set to 100,000 .

Let ${ }_{j} \mathrm{~L}_{i}(x)$ denote the total person-years lived in region $i$, during the 5-year age interval $(x, x+5)$ by individuals who were born in region $j$. Assuming a uniform distribution of outmigrations and deaths over the 5-year. unit interval of age, we may define the following multiregional generalization of the single-region linear integration formula for deriving $L(x)$ :

$$
j_{i}^{L_{i}}(x)=\frac{5}{2}\left[j_{i}^{\ell}(x)+j_{i}^{\ell}(x+5)\right]
$$




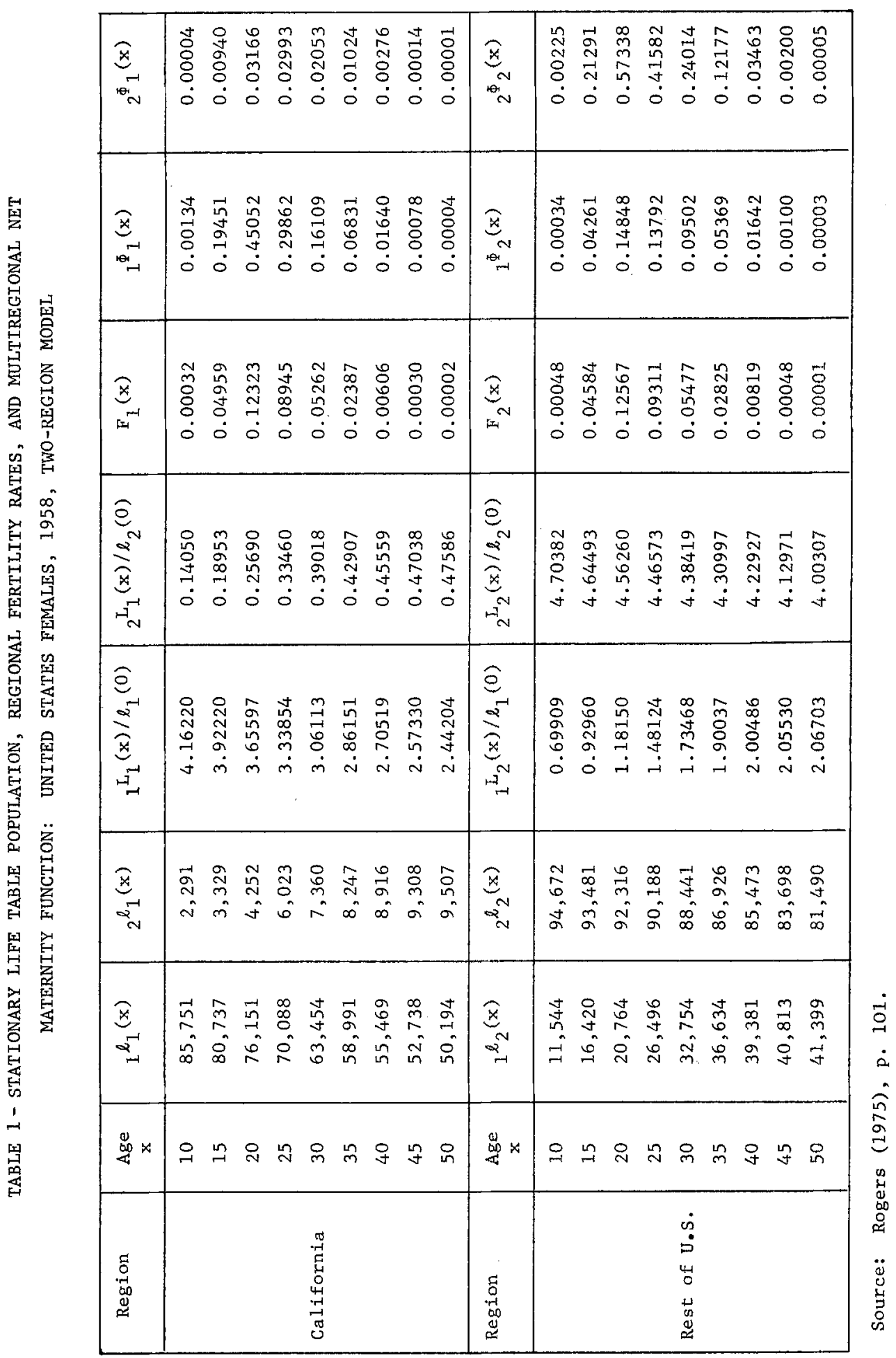


We have estimated the number of California-born life table survivors at age 15 in the rest of the United States to be 16,420. Table 1 gives 11,544 as the corresponding total for those 5 years younger. Hence the total number of person-years lived in the rest of the United States between ages 10 and 15 by the 100,000 California-born females is

$$
\begin{aligned}
L_{2} L_{2}(10) & =\frac{5}{2}\left[1_{1}^{l_{2}}(10)+{ }_{1} l_{2}(15)\right] \\
& =\frac{5}{2}[11,544+16,420] \\
& =69,909,
\end{aligned}
$$

or 0.69909 years per California-born female.

The remainder of the multiregional life table follows directly. First, we complete the survivorship and migration history of the multiregional cohort of babies. Next, we compute the total person-years in prospect beyond age $\mathrm{x}$ by region of residence, ${ }_{j} \mathrm{~T}_{i}(x)$ say, for each birth cohort $\ell_{j}(0)$, where

$$
j_{i}^{T}(x)=\sum_{y=x}^{z} j_{i}^{L}(y), z \text { being the last age interval of life. The }
$$

expectation of 1 ife beyond age $x$ for $j$-born individuals then follows directly as:

$$
j^{e(x)}=\frac{\sum_{i=1}^{m} j^{T_{i}(x)}}{\sum_{i=1}^{m} j^{\ell_{i}(x)}}=\frac{j^{T(x)}}{j^{\ell(x)}},
$$

and

$$
j_{i}(x)=\frac{i_{i}^{T_{i}}(x)}{\sum_{i=1}^{m} j_{i}^{l}(x)}=\frac{j_{i}^{T_{i}(x)}}{j^{\ell(x)}}
$$

Thus, we conclude that a $j$-born individual currently at age $x$ can expect to live a total of $j^{e(x)}$ more years, of which $j^{e}{ }_{j}(x)$ years will be spent in region $j$ and $j e_{i}(x)$ years will be spent in region $i, i=1,2, \ldots, m,(i \neq j)$. 
Summing the various columns of person-years lived in Table 1 and adding to these totals the person-years lived by those under age 10 and over age 55, we may find the total person-years lived beyond each age, by region of residence and birth, and the corresponding expectations of remaining life at each age. From such calculations we conclude, for example, that a California-born baby girl, under the regional mobility and mortality schedules that prevailed in the United States in 1958, has an expectation of life at birth of 73.86 years of which 24.90 years, on the average, will be lived in the rest of the United States. A baby gir1 born in the rest of the United States, on the other hand, has a life expectancy of 73.11 years, of which only 5.75 years, on the average, will be lived in California.

Table 2 presents the regional expectations of life at birth by region of residence for the same 1958 data that generated Table 1 but disaggregates California into four regions: the San Francisco, Los Angeles, and San Diego Standard Metropolitan Statistical Areas, and the rest of California. For purposes of comparison, the corresponding expectations of life at birth for males are also included.

The data in Table 2 indicate that the migration patterns of males and females are remarkably similar; with males exhibiting slightly higher levels of geographical mobility. (The proportions of expected lifetimes to be lived in the regions of birth are higher for females born in a11 but the rest of California region.) The heaviest migration level out of California occurs in the San Diego region, where almost a half ( 45 to 47 percent) of a baby's expected lifetime is expected to be lived outside of California. This no doubt is due to the large number of births that are attributable to Navy and other military personnel stationed in that region. 
TABLE 2 - REGIONAL EXPECTATIONS OF LIFE AT BIRTH

BY REGION OF RESIDENCE: UNITED STATES MALES AND FEMALES, 1958, FIVE-REGION MODEL

A. Males

\begin{tabular}{|l|r|r|r|r|r|r|}
\hline \multirow{2}{*}{$\begin{array}{l}\text { Region of } \\
\text { Birth }\end{array}$} & \multicolumn{5}{|c|}{ Region of Residence } & \multirow{2}{*}{ Tota1 } \\
\cline { 2 - 7 } & 1. & 2. & 3. & 4. & 5. & \\
\hline 1. San Francisco S.M.S.A. & 32.51 & 5.50 & 1.10 & 5.59 & 22.92 & 67.62 \\
2. Los Angeles S.M.S.A. & 4.11 & 36.06 & 1.56 & 3.62 & 22.16 & 67.50 \\
3. San Diego S.M.S.A. & 3.64 & 7.67 & 21.72 & 2.46 & 31.95 & 67.44 \\
4. Rest of California & 8.81 & 7.39 & 1.27 & 27.09 & 22.78 & 67.35 \\
5. Rest of U.S. & 1.34 & 2.69 & 0.58 & 0.87 & 61.26 & 66.74 \\
\hline
\end{tabular}

\section{B. Females}

\begin{tabular}{|l|r|r|r|r|r|r|}
\hline \multirow{2}{*}{$\begin{array}{l}\text { Region of } \\
\text { Birth }\end{array}$} & \multicolumn{5}{|c|}{ Region of Residence } & \multirow{2}{*}{ Total } \\
\cline { 2 - 7 } & 1. & 2. & 3. & 4. & 5. & \\
\hline 1. San Francisco S.M.S.A. & 35.96 & 6.61 & 1.18 & 6.02 & 24.22 & 73.98 \\
2. Los Angeles S.M.S.A. & 4.77 & 40.81 & 1.79 & 3.82 & 22.97 & 74.15 \\
3. San Diego S.M.S.A. & 4.22 & 9.05 & 24.63 & 2.61 & 33.26 & 73.78 \\
4. Rest of California & 10.59 & 9.09 & 1.37 & 27.97 & 24.71 & 73.73 \\
5. Rest of U.S. & 1.42 & 2.99 & 0.55 & 0.83 & 67.35 & 73.14 \\
\hline
\end{tabular}

Source: Rogers (1975), p. 72 . 


\section{The Discrete Mode1 of Multiregiona1 Demographic Growth}

Population projections work out the numerical consequences to an initial population of a particular set of assumptions regarding future fertility, mortality, and geographical mobility. The mechanics of such projections typically revolve around three basic steps. The first ascertains the starting age distribution and the age-specific schedules of fertility, mortality, and migration to which this population has been subject during a past period. The second adopts a set of assumptions regarding the future behavior of such schedules. And the third derives the consequences of applying these schedules to the initial population.

The discrete model of multiregional demographic growth expresses the population projection process by means of a matrix operation in which a multiregional population, set out as a vector, is multiplied by a projection matrix that survives that population forward through time [Rogers (1975), Ch. 5]. The projection calculates the region and age-specific survivors of a multiregional population of a given sex and adds to this total the new births that survive to the end of the unit time interval. This process may be described by the following system of equations:

$$
\begin{aligned}
& \mathrm{K}_{i}^{(t+1)}(0)=\sum_{x=\alpha-5}^{\beta-5} \sum_{j=1}^{m} \mathrm{~b}_{j i}(\mathrm{x}) \mathrm{k}_{j}^{(\mathrm{t})}(\mathrm{x}) \quad \begin{array}{l}
\alpha-5 \leq \mathrm{x} \leq \beta-5, \\
i=1,2, \ldots, m
\end{array} \\
& K_{i}^{(t+1)}(x+5)=\sum_{j=1}^{m} s_{j i}(x) K_{j}^{(t)}(x) \quad \begin{array}{l}
x=0,5,10, \ldots, z \\
i=1,2, \ldots, m
\end{array}
\end{aligned}
$$

where we continue to assume a time and age interval of 5 years, and where

$\mathrm{b}_{\mathbf{j i}}(\mathrm{x})=$ the average number of (female) babies born during a 5-year unit interval and alive in region $i$ at the end of that interval, per (female) person in region $j$ aged $x$ to $x+4$ years at the beginning of the interval; 
$s_{j i}(x)=$ the probability that a (female) resident of region $j$ aged $\mathrm{x}$ to $\mathrm{x}+4$ years will be alive and in region $i 5$ years later;

$\mathrm{K}_{\mathrm{j}}^{(\mathrm{t})}(\mathrm{x})=$ the (female) population in region $\mathrm{j}$ aged $\mathrm{x}$ to $\mathrm{x}+4$ years at time $\mathrm{r}$;

$\alpha=$ the first age of childbearing;

$\beta=$ the last age of childbearing;

$z=$ the last age interval of life (e.g., 85 years and over).

As in the single-region model, survival of individuals from one moment in time to another, 5 years later, is calculated by diminishing a regional population to take into account the decrement due to mortality. In the multiregional mode1, however, we also need to include the decrement due to outmigration and the increment contributed by inmigration. An analogous problem is presented by surviving children born during the 5-year interval. Some of these migrate with their parents; others are born after their parents have migrated but before the unit time interval has elapsed.

In the United States an estimated $446,634\left[=\mathrm{K}_{1}^{(t)}(20)\right]$ and $5,149,902$ $\left[=\mathrm{K}_{2}^{(\mathrm{t})}(20)\right]$ women, aged 20 to 24 years at last birthday, were living in California and in the rest of the United States, respectively, at mid-year of 1958. Recalling the two-region 1ife table population for California and the rest of the United States that appears in Table 1 and using the appropriate formula for $s_{i i}(x)$ [see Rogers (1975), p. 79] we may compute, for example,

$$
s_{11}(20)=\frac{\frac{1^{L_{1}(25)}}{I_{2}(20)}-\frac{2^{L_{1}(25)}}{2_{2}(20)}}{\frac{1 L_{1}(20)}{L_{2}(20)}-\frac{2^{L_{1}(20)}}{L_{2}(20)}}=\frac{\frac{3.33854}{1.18150}-\frac{0.33460}{4.56260}}{\frac{3.65597}{1.18150}-\frac{0.25690}{4.56260}}=0.90596 .
$$

Analogous calculations yield the outmigration proportion $s_{21}(20)=0.02212$. 
The sum of the two products $s_{11}(20) \mathrm{K}_{1}^{(t)}(20)$ and $s_{21}(20) \mathrm{K}_{2}^{(t)}(20)$ gives the expected number of women aged 25 to 29 in California in 1963 [Equation (6)]:

$$
\begin{aligned}
\mathrm{K}_{1}^{(t+1)}(25) & =(0.90596)(466,634)+(0.02232)(5,149,902) \\
& =537,719 .
\end{aligned}
$$

Utilizing the appropriate formula for the fertility rates $b_{i j}(x)$ [see Rogers (1975), p. 12] we may calculate the contribution made to the first age group in the rest of the United States in 1963 by surviving female children of 20-to 24-year-old women residents of California in 1958:

$$
\begin{aligned}
b_{12}(20) & =\frac{1}{2}\left[(0.11260) F_{1}(20)+(0.90596)(0.11260) F_{1}(25)\right. \\
& \left.+(0.09050)(4.90700) F_{2}(25)\right],
\end{aligned}
$$

into which we may substitute $F_{1}(20)=0.12323, F_{1}(25)=0.08945$, and $F_{2}(25)=0.09311$ to find

$\mathrm{b}_{12}(20)=0.03217$.

Applying this rate to the estimated 446,634 females in California aged 20 to 24 years in 1958, we find their contribution to the first age group in the rest of the United States in 1963 to be $446,634(0.03217)=14,368$ girls. Adding this total to the corresponding contribution made by 20-to 24-year-old females in the rest of the United States in 1958 we obtain the total contribution to $\mathrm{K}_{2}^{(\mathrm{t}+1)}(0)$ made by U.S. women aged 20 to 24 in 1958, and aggregating all such totals across the childbearing ages [Equation (5)], we find $\mathrm{K}_{2}^{(t+1)}(0)=9,638,313$, the resident population aged 0 to 4 at last birthday in the United States at mid-year 1963. Adding this total to the resident population at all other ages gives the rest of the United States a projected grand total of $86,612,665$ females for 1963. California's projected total female population for the same year is $8,646,045$. In Table $3 \mathrm{~B}$ we find that the corresponding totals in 1958 were $80,844,419$ and $7,395,438$, respectively. 
It is well known that a regional population which is closed to (i.e., undisturbed by) migration wil1, if subjected to an unchanging regime of mortality and fertility, ultimately achieve a stable constant age composition that increases at a constant stable growth ratio, $\lambda$ say. In Rogers (1975) it is shown that this same property abtains region-by-region in the case of a multiregional population system the totality of which is closed to migration and subjected to an unchanging multiregional schedule of mortality, fertility, and internal migration. Knowledge of the asymptotic properties of such a population projection helps us understand the meaning of observed age-specific birth, death, and migration rates. In particular, the quantity $r=0.2 \ln \lambda$ gives the intrinsic rate of growth that is implied by the indefinite continuation of observed schedules of mortality, fertility, and migration. Table 3 shows that this rate is 0.02064 in the 2-region projection and 0.02065 in the 5-region projection. Both rates are below the 0.02070 yielded by the single-region model. The differences are a consequence of aggregation bias.

A related but equally useful demographic measure is the stable equivalent $Y$ (Keyfitz, 1969) of each region and its proportional allocation across age groups in that region, $C_{i}(x)$, which is the region's stable age composition. The former may be obtained by projecting the observed multiregional population forward until it becomes stable and dividing the resulting age-region-specific totals by the stable growth ratio $\lambda$ raised to the $n^{\text {th }}$ power, where $n$ is the number of iterations that were needed to achieve stability. Suming across al1 age groups in a region gives the regional stable equivalent $Y_{i}$, whilst dividing the number in each age group in region $i$ by $Y_{i}$ gives $C_{i}(x)$, region $i$ 's age composition at stability. Finally, dividing each region's stable equivalent by the sum total of all regional stable equivalents gives (\%) ${ }_{1}$, the stable regional share of the total multiregional population in region $i$ at stability. 
Table 3 presents the above described demographic measures for our California-rest of the United States data of 1958. Also included are intrinsic rates of birth, death, and migration. Note that if the 1958 schedules of growth were to continue unchanged, California's population would ultimately stabilize at about 18 percent of the national total (doubling its 1958 share) and would increase at an annual rate of approximately 20.6 per 1000. Three-fourths of California's stable population would reside in the San Francisco and Los Angeles SMSAs and about one-third of the population would be under 15 years of age. Net migration into the state would be positive, but both the San Diego SMSA and the rest of California each would experience a slight net outmigration of about 0.4 per 1000 . Both the highest birth rate and the highest proportion of the aged would be found in the San Diego SMSA, a reflection of San Diego's dual roles as military base and retirement haven. 
TABIE 3 - MULTIREGIONAL PROJECTIONS TO STABILITY AND ASSOCIATED

PARAMETERS: UNITED STATES FEMALES, 1958

A. FIVE-REGION PROJECTION

\begin{tabular}{|c|c|c|c|c|c|}
\hline \multirow{2}{*}{$\begin{array}{l}\text { Projections } \\
\text { and Stable } \\
\text { Growth } \\
\text { Parameters }\end{array}$} & \multicolumn{5}{|c|}{ REGION OF RESIDENCE } \\
\hline & $\begin{array}{c}\text { 1. San Francisco } \\
\text { S.MSA. }\end{array}$ & $\begin{array}{c}\text { 2. Los Angeles } \\
\text { SMSA. }\end{array}$ & $\begin{array}{l}\text { 3. San Diego } \\
\text { SMSA. }\end{array}$ & 4. Rest of $\mathrm{Cal}$. & 5. Rest of U.S. \\
\hline $\mathrm{K}(1958)$ & $1,941,994$ & $3,723,919$ & 446,390 & $1,283,135$ & $80,844,419$ \\
\hline$\%(1958)$ & 0.0220 & 0.0422 & 0.0051 & 0.0145 & 0.9162 \\
\hline$K(2008)$ & $7,561,538$ & $14,488,817$ & $2,334,043$ & $4,634,969$ & $180,567,030$ \\
\hline$\%(2008)$ & 0.0361 & 0.0691 & 0.0112 & 0.0221 & 0.8615 \\
\hline $\mathrm{Y}$ & $3,620,347$ & $6,612,727$ & $1,023,696$ & $2,210,093$ & $61,171,949$ \\
\hline$\%$ & 0.0485 & 0.0886 & 0.0137 & 0.0296 & 0.8196 \\
\hline$C(0-14)$ & 0.3275 & 0.3297 & 0.3404 & 0.3520 & 0.3456 \\
\hline C(15-64) & 0.5953 & 0.5904 & 0.5570 & 0.5717 & 0.5828 \\
\hline$c(65+)$ & 0.0773 & 0.0799 & 0.1027 & 0.0763 & 0.0716 \\
\hline$\lambda$ & \multicolumn{5}{|c|}{1.10878} \\
\hline$r$ & \multicolumn{5}{|c|}{0.02065} \\
\hline b & 0.02593 & 0.02612 & 0.02826 & 0.02780 & 0.02744 \\
\hline$\Delta=b-r$ & 0.00528 & 0.00547 & 0.00760 & 0.00714 & 0.00679 \\
\hline $\mathrm{d}$ & 0.00652 & 0.00628 & 0.00721 & 0.00676 & 0.00665 \\
\hline$i$ & 0.02242 & 0.01832 & 0.03163 & 0.02920 & 0.00245 \\
\hline o & 0.02117 & 0.01751 & 0.03202 & 0.02958 & 0.00259 \\
\hline $\mathrm{n}$ & 0.00125 & 0.00081 & -0.00039 & -0.00039 & -0.00014 \\
\hline
\end{tabular}

B. TWO-REGION AND AGGREGATED MULTIREGIONAL PROJECTIONS

\begin{tabular}{|c|c|c|c|c|c|}
\hline \multirow{2}{*}{$\begin{array}{l}\text { Projections } \\
\text { and Stable } \\
\text { Growth } \\
\text { Parameters }\end{array}$} & \multicolumn{2}{|c|}{ TWO-REGION MODEL } & \multicolumn{2}{|c|}{$\begin{array}{c}\text { AGGREGATIONS OF } \\
\text { MULTIREGIONAL MODELS }\end{array}$} & \multirow{2}{*}{$\begin{array}{l}\text { SINGLE- } \\
\text { REGION } \\
\text { MODEL }\end{array}$} \\
\hline & 1. California & 2. Rest of U.S. & TWO-REGION & ETVE-REGION & \\
\hline $\mathrm{K}(1958)$ & $7,395,438$ & $80,844,419$ & $88,239,857$ & $88,239,857$ & $88,239,857$ \\
\hline$K(2008)$ & $28,704,425$ & $180,787,223$ & $209,491,647$ & $209,586,397$ & $209,416,093$ \\
\hline $\mathrm{Y}$ & $13,182,724$ & $61,427,080$ & $74,609,804$ & $74,638,813$ & $74,172,787$ \\
\hline$\%$ & 0.1767 & 0.8233 & 1.0000 & 1.0000 & 1.0000 \\
\hline $\mathrm{C}(0-14)$ & 0.3337 & 0.3456 & 0.3435 & 0.3435 & 0.3443 \\
\hline$C(15-64)$ & 0.5865 & 0.5828 & 0.5835 & 0.5834 & 0.5835 \\
\hline$c(65+)$ & 0.0798 & 0.0716 & 0.0730 & 0.0732 & 0.0722 \\
\hline$\lambda$ & \multicolumn{2}{|c|}{1.10874} & 1.10874 & 1.10878 & 1.10905 \\
\hline$I$ & \multicolumn{2}{|c|}{0.02064} & 0.02064 & 0.02065 & 0.02070 \\
\hline b & 0.02651 & 0.02744 & 0.02728 & 0.02727 & 0.02734 \\
\hline$\Delta=\mathrm{b}-\mathrm{r}=\mathrm{d}$ & 0.00587 & 0.00680 & 0.00663 & 0.00662 & 0.00664 \\
\hline
\end{tabular}




\section{The Continuous Model of Multiregional Demographic Growth}

The principal contribution of the continuous model of demographic growth lies in its ability to trace through the ultimate consequences of applying a given schedrle of fixed age-specific rates of fertility, mortality, and migration to a population of a single sex. It is, therefore, a natural generalization of the multiregional life table's stationary population whose total births are equal to total deaths. When births are not forced to equal deaths, but instead are assumed to occur according to rates that are forever fixed, we obtain the more interesting model of a stable multiregional population. By associating the births of a current generation with those of a preceding generation, one can develop several important constants that describe the ultimate growth and regional age distributions of such a population.

A continuous model of single-sex population growth may be defined for a multiregional population system by means of a straightforward generalization of the corresponding single-region mode1. Beginning with the number of female births at time $t$ in each region, $B_{i}(t)$, say, we note that the number of women aged $x$ to $x+d x$ in region $i$ at time $t$, were born since time zero and are survivors of those born $x$ years ago anywhere in the multiregional system and now living

in region $i$ at age $x$, that is $\sum_{j=1} B_{j}(t-x) j_{j}{ }^{(x) d x}$, where $x \leq t$. At time $t$, these women give birth to

$$
\left[\sum_{j=1}^{m} B_{j}(t-x)_{j} p_{i}(x)\right]_{i}(x) d x
$$

children in region $i$ per year. Here ${ }_{j} \mathrm{p}_{i}(x)$ denotes the probability that a baby girl born in region $j$ will survive to age $x$ in region $i$, and $m_{i}(x) d x$ is the annual rate of female childbearing among women aged $x$ to $x+d x$ in region $i$.

Integrating the above expression over all $x$ and adding $w_{i}(t)$ to include births to women already alive at time zero gives the fundamental integral 
equation system

$$
B_{i}(t)=w_{i}(\varepsilon)+\int_{0}^{t}\left[\sum_{j=1}^{m} B_{j}(t-x){ }_{j} p_{i}(x)\right] m_{i}(x) d x, \quad i=1,2, \ldots, m(7)
$$

For all $t$ beyond the last age of childbearing, those surviving from time zero will no longer contribute to current births, i.e., $w_{i}(t)=0$ for $t>\beta$, and (7) then reduces to the homogeneous equation system

$$
\begin{array}{r}
B_{i}(t)=\int_{0^{j}}^{t} \sum_{j=I}^{m} B_{j}(t-x){ }_{j} P_{i}(x) m_{i}(x) d x=\int_{0^{j}}^{t} \sum_{j=1}^{m} B_{j}(t-x) j_{i}{ }_{i}(x) d x \\
t>B \quad i=1,2, \ldots, m,
\end{array}
$$

where $j^{\Phi_{i}}(x)={ }_{j}^{p} p_{i}(x) m_{i}(x)$ is the multiregional generalization of the net maternity function of the single-region model (Keyfitz, 1968, Ch.6). With this multiregional net maternity function we may associate the moments

$$
j_{i} R_{i}(n)=\int_{\alpha}^{\beta} x^{n} j_{i}(x) d x \quad i, j=1,2, \ldots, m
$$

among which $\mathrm{j}_{j}(0)$ is of particular interest inasmuch as it defines the number of (gir1) children expected to be born in region $i$ to a (gir1) baby now born in region $j$. Summing this measure over regions of residence we find the region-of-birth reproduction rate for region $j$ :

$$
j^{R(0)}={ }_{j} R_{1}(0)+j_{j}(0)+\ldots=\sum_{i=1}^{m}{ }_{j} R_{i}(0)
$$

Alternatively, summing the same measure over regions of birth we obtain the region-of-residence reproduction rate for region $i$ :

$$
R_{i}(0)=\frac{B_{1}}{B_{i}}{ }_{1}^{R_{i}}(0)+\frac{B_{2}}{B_{i}} 2^{R_{i}}(0)+\ldots=\sum_{j=1}^{m} \frac{B_{j}}{B_{i}}{ }_{j}^{R_{i}}(0),
$$

where the weights introduced into the summation reflect the total number of births in each region. 
As in the single-region model, the solution of (7) can be found by first obtaining a solution of ( 8 ) and then choosing values for the arbitrary constants in that solution so that in addition to satisfying (8), $B_{j}(t)$ also satisfies (7). Following the procedure used in the single-region model (e.g., Keyfitz, 1968, Ch.5) we adopt the trial solution $B_{i}(t)=Q_{i} e^{r t}$ and rewrite (8) as

$$
Q_{i}=\int_{\alpha}^{B} \sum_{j=1}^{m} Q_{j} e^{-r x}{ }_{j} P_{i}(x) m_{i}(x) d x, i=1,2, \ldots, m,
$$

where the range of integration has been narrowed to take into account that $m_{i}(x) \neq 0$ only for $\alpha \leq x \leq \beta$. Finally, dividing both sides of the equation by $Q_{i}$ gives the multiregional characteristic equation system

$$
1=\sum_{j=1}^{m} \frac{Q_{j}}{Q_{i}} \Psi_{i}(r), \quad i=1,2, \ldots, m,
$$

where $\dot{j}_{i}(r)=\int_{\alpha}^{\beta} e^{-r x} j_{j} p_{i}(x) m_{i}(x) d x=\int_{\alpha}^{\beta} e^{-r x} j_{j}(x) d x$.

Single-region arguments may be used to show that the system of equations in (12) can have only one real root and that any complex roots which satisfy (12), must occur in complex conjugate pairs (Keyfitz, 1968, Ch.5). Furthermore, the real root $r$ is greater than the real part of any complex root. Consequently, the birth sequence $B_{i}(t)=\sum_{h=1}^{\infty} Q_{h i} e^{r_{h} t}$ is increasingly dominated by the first term $Q_{1 i} e^{r_{1} t}$ as $t$ becomes large. Thus, ultimately

$$
B_{i}(t) \doteqdot Q_{1 i} e^{r_{1} t}=Q_{i} e^{r t}
$$

Exponential births lead to an exponentially growing population with a stable distribution in which each age-by-region subpopulation maintains a constant proportional relationship to the total population and increases at the same intrinsic rate of growth, $r$. The influence of the initial population distribution is forgotten as time goes by, a condition known as ergodicity. 
In the single-region model one normally evaluates $\Psi(x)$ with the numerical approximation

$$
\Psi(x)=\sum_{x=\alpha}^{B-5} e^{-r(x+2.5)} \frac{L(x) F(x)}{l(0)}
$$

in which the integral $\int_{0}^{5} e^{-r(x+t)} p(x+t) m(x+t) d t$ is replaced by the product of $e^{-r(x+2.5)}, \frac{L(x)}{2(0)}$, and $F(x)$, the observed fertility rate. The summation is over ages $\mathrm{x}$ which are multiples of 5 .

An analogous approach may be followed in the multiregional model. We evaluate the integral

$$
\int_{0}^{5} e^{-r(x+t)} j_{j} p_{i}(x+t) m_{i}(x+t) d t
$$

as the product of $e^{-r(x+2.5)}, \frac{j^{L_{i}(x)}}{l_{j}(0)}$, and $F_{i}(x)$.

Thus we have

$$
j_{i}^{\Psi_{i}}(r)=\sum_{x=\alpha}^{\beta-5} e^{-r(x+2.5)} \frac{j_{i}^{L_{i}}(x) F_{i}(x)}{\ell_{j}(0)}
$$

Using the data set out in Table 1, we may compute, for example,

$$
2^{\mathscr{H}_{1}}(0)={ }_{2} \mathrm{R}_{1}(0)=\sum_{x=10}^{50} \frac{2^{L_{1}}(\mathrm{x})}{\ell_{2}(0)} \quad \mathrm{F}_{1}(\mathrm{x})=0.105,
$$

which defines the number of baby girls by which a woman born in the rest of the United States will be replaced in California. Analogous computations give

$$
{ }_{1} \mathrm{R}_{1}(0)=1.192 \quad 1_{1}^{\mathrm{R}_{2}(0)=0.495 \quad 2^{\mathrm{R}_{2}(0)}=1.603} .
$$

We conclude therefore, that under the 1958 schedule of growth, a girl born in the rest of the United states will be replaced, in the subsequent generation, by $2^{R(0)}=0.105+1.603=1.708$ baby girls of whom 0.105 will be born in California. Corresponding measures for a California-born girl are 1.687 and 0.495 , respectively. 
But $r=0$ is clearly not the solution of Equation (12). This can be readily established by substituting the values of $j_{i}(0)$ into (12) and solving for $Q_{2} / Q_{1}$ and $Q_{1} / Q_{2}$, respectively. Solving the first equation we obtain $Q_{2} / Q_{1}=-1.829$; the solution to the second is $Q_{1} / Q_{2}=-1.218$ or, equivalently, $Q_{2} / Q_{1}=-0.821$. Since we have two different estimates of the same quantity it is clear that we have not yet found the correct value for $r$. By a process of iteration we ultimately converge to $x=0.02059$, for which

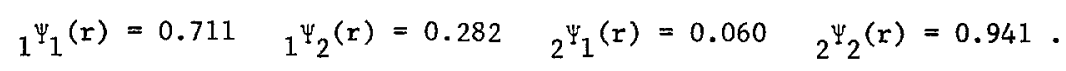

Substituting these into Equation (12) gives $Q_{2} / Q_{1}=4.823$ in both cases, i.e.,

$$
\begin{aligned}
0.711+(4.823) 0.060 & =1 \\
(1 / 4.823) 0.282+0.941 & =1
\end{aligned}
$$




\section{The Spatial Consequences of Zero Population Growth}

During the past decade, several White House task forces, countless congressional committees, and scores of public interest groups have attempted to define the outlines of a desirable national population growth policy, taking as their starting point the widespread conviction that such growth is not taking place the way it should. Even though these committees and task forces span more than a decade and several administrations, their respective products have been remarkably similar in coverage, major themes, and proposals. Most begin by projecting the nation's population growth to a net increase of anywhere from 80 to 145 million Americans by the turn of the century. Almost all of these study groups then assert that without public intervention, a majority of citizens will inherit steadily growing, already overcrowded and poorly planned metropolitan areas. (See, for example, the various reports of the U.S. Commission on Population Growth and the American Future, 1972.)

The contention that America's population crisis stems from a propensity to overbreed overlooks the evident fact that any demographic imbalance in the U.S. today is less one of absolute numbers than of their maldistribution. The notion of a population distribution policy therefore has wide appeal but, unfortunately, insufficient substance. An important contributing factor to this lack of substance is our poor understanding of the dynamics of multiregional demographic growth and distribution.

Demographers agree that because of the large number of young people in America's population today, immediate zero population growth is not a practical objective. Consequently, most projected paths toward a stationary population assume an average of approximately 2.11 births per woman from now on and hold mortality fixed. On the assumption of zero or negligibly small net immigration, such a projection leads in about 70 years to a stationary population that is 
approximately 40 to 50 percent larger than the current population. Much has been made of the social and economic consequences of such a population and particularly important have been the analyses of its stationary age composition-an age composition that would have a higher median age and virtually constant numbers from age zero to 50. (See, for example, Coale, 1972.)

But what of the spatial distribution of such a stationary national population? What are the alternative paths in a geographic context? Will we, for example have as Alonso (1973, p. 191) puts it "a nationally stable population ... composed of many localities declining in population, many localities growing, and only some remaining stable"?

A nationally stationary population may arise out of a growth process which exhibits a zero growth rate in each short interval of time or it may develop out of a long-run average zero growth rate which occurs as a consequence of a combination of sequences of positive growth, of zero growth, and of decline. Since no obvious advantages arise from the latter case, demographers quite naturally have viewed the attainment of a stationary population as arising from a continuation of zero growth in the short-run. Thus the normal assumption involves a fixed mortality schedule and fertility set at replacement level. An analogous situation arises in the case of a multiregional population. By augmenting the assumptions of fixed mortality and replacement level fertility with the assumption of fixed migration we may obtain a stationary multiregional population. In such a case, each region in the system will grow at a zero rate of growth. (Alternatively, we may assume that zero growth for the multiregional system is a consequence of an aggregation of zero and nonzero growth rates in its constituent regions. The dynamics of this situation are more complex and will not be considered in this paper.) 
If mortalicy is fixed and one thousand baby girls born at each moment replace themselves, on the average, with a thousand baby girls as they move past their childbearing years, we will ultimately obtain a stationary zero growth population. But the women who survive to the childbearing ages must have enough daughters to replace not only themselves but also those women who have not survived to become mothers. Thus we specify that the net (and not the gross) reproduction rate of the female population be unity, i.e., $\mathrm{R}(0)=1$. Reducing observed age-specific fertility rates proportionally to obtain a net reproduction rate of unity then is one way of achieving a stationary population. The last column in the lower half of Table 4 shows that had the U.S. female population in 1958 immediately moved to reptacement sevels, the 88 million female population of that year would have grown to 113 million (the stationary equivalent, $Y$ ) before attaining zero population growth.

The multiregional analog of the above calculation is straightforward. We simply reduce the observed age-specific regional fertility rates proportionally until region-of-birth net reproduction rates are all equal to unity, $1 . e .$, $j^{R(0)}=1, j=1,2, \ldots, \mathrm{m}$. The mechanics of the population projection process itself, however, remain unchanged.

Table 4 sets out some of the more interesting consequences of an immediate movement to replacement levels of fertility by the 1958 U.S. female population. that has served as our numerical example throughout this paper. (Note that Table 4 is the zero growth counterpart of Table 3 , which illuminated the 1ong-run consequences of an unchanging continuance of present rates.) Several findings are of some interest and merit elaboration.

First, observe that the spatial allocations or shares of the stationary multiregional population in Table 4 do not differ significantly from those of 
TABLE 4 - MULTIREGIONAL PROJECTIONS TO ZERO GROWTH AND ASSOCIATED PARAMETERS: UNITED STATES FEMALES, 1958

\section{A. FIVE-REGION PROJECTION}

\begin{tabular}{|c|c|c|c|c|c|}
\hline \multirow{2}{*}{$\begin{array}{l}\text { Projections } \\
\text { and Stable } \\
\text { Growth } \\
\text { Parameters }\end{array}$} & \multicolumn{5}{|c|}{ REGION OF RESIDENCE } \\
\hline & $\begin{array}{l}\text { 1. San Francisco } \\
\text { S.M.S.A. }\end{array}$ & $\begin{array}{l}\text { 2. Los Angeles } \\
\text { S.M.S.A. }\end{array}$ & $\begin{array}{l}\text { 3. San Diego } \\
\text { S.M.S.A. }\end{array}$ & 4. Rest of Cal. & 5. Rest of U.S. \\
\hline $\mathrm{K}(1958)$ & $1,941,994$ & $3,723,919$ & 446,390 & $1,283,135$ & $80,844,419$ \\
\hline$\%(1958)$ & 0.0220 & 0.0422 & 0.0051 & 0.0145 & 0.9162 \\
\hline $\mathrm{K}(2008)$ & $4,132,157$ & $7,869,750$ & $1,216,643$ & $2,398,295$ & $95,274,261$ \\
\hline$\%(2008)$ & 0.0373 & 0.0710 & 0.0110 & 0.0216 & 0.8592 \\
\hline $\mathrm{Y}$ & $5,887,834$ & $10,558,059$ & $1,546,379$ & $3,337,595$ & $92,180,796$ \\
\hline$\%$ & 0.0519 & 0.0930 & 0.0136 & 0.0294 & 0.8121 \\
\hline$c(0-14)$ & 0.1997 & 0.1960 & 0.1705 & 0.1979 & 0.2014 \\
\hline $\mathrm{c}(15-64)$ & 0.6296 & 0.6223 & 0.5874 & 0.6212 & 0.6309 \\
\hline $\mathrm{C}(65+)$ & 0.1707 & 0.1818 & 0.2422 & 0.1810 & 0.1677 \\
\hline$\lambda_{i}$ & \multicolumn{5}{|c|}{1.00000} \\
\hline$\underline{r}$ & \multicolumn{5}{|c|}{0.00000} \\
\hline$\underline{b}$ & 0.01359 & 0.01317 & 0.01178 & 0.01315 & 0.01375 \\
\hline$\Delta=b-r$ & 0.01359 & 0.01317 & 0.01178 & 0.01315 & 0.01375 \\
\hline $\mathrm{d}$ & 0.01334 & 0.01305 & 0.01599 & 0.01438 & 0.01366 \\
\hline$i$ & 0.01906 & 0.01624 & 0.03167 & 0.02775 & 0.00224 \\
\hline o & 0.01931 & 0.01636 & 0.02746 & 0.02651 & 0.00233 \\
\hline $\mathrm{n}$ & -0.00025 & -0.00012 & 0.00421 & 0.00124 & -0.00009 \\
\hline
\end{tabular}

B. TWO-REGION AND AGGREGATED MULTIREGIONAL PROJECTIONS

\begin{tabular}{|c|c|c|c|c|c|}
\hline \multirow{2}{*}{$\begin{array}{l}\text { Projections } \\
\text { and Stable } \\
\text { Growth } \\
\text { Parameters }\end{array}$} & \multicolumn{2}{|c|}{ TWO-REGION MODEL } & \multicolumn{2}{|c|}{$\begin{array}{c}\text { AGGREGATIONS OF } \\
\text { MULTIREGIONAL MODELS }\end{array}$} & \multirow{2}{*}{$\begin{array}{l}\text { SINGLE- } \\
\text { REGION } \\
\text { MODEL }\end{array}$} \\
\hline & 1. California & 2. Rest of U.S. & TWO-REGION & FIVE-REGION & \\
\hline$K(1958)$ & $7,395,438$ & $80,844,419$ & $88,239,857$ & $88,239,857$ & $88,239,857$ \\
\hline$K(2008)$ & $15,442,904$ & $95,404,038$ & $110,846,942$ & $110,891,106$ & $110,653,183$ \\
\hline$\underline{Y}$ & $20,765,005$ & $92,670,056$ & $113,435,061$ & $113,512,666$ & $112,988,412$ \\
\hline$\%$ & 0.1831 & 0.8169 & 1.0000 & 1.0000 & 1.0000 \\
\hline$C(0-14)$ & 0.1927 & 0.2014 & 0.1998 & 0.1997 & 0.2003 \\
\hline$C(15-64)$ & 0.6249 & 0.6310 & 0.6299 & 0.6296 & 0.6308 \\
\hline$C(65+)$ & 0.1824 & 0.1676 & 0.1703 & 0.1707 & 0.1689 \\
\hline$\lambda$ & \multicolumn{2}{|c|}{1.00000} & 1.00000 & 1.00000 & 1.00000 \\
\hline$\underline{r}$ & \multicolumn{2}{|c|}{0.00000} & 0.00000 & 0.00000 & 0.00000 \\
\hline $\mathrm{b}$ & 0.01322 & 0.01375 & 0.01365 & 0.01364 & 0.01369 \\
\hline$\Delta=\mathrm{b}-\mathrm{r}=\mathrm{d}$ & 0.01322 & 0.01375 & 0.01365 & 0.01364 & 0.01369 \\
\hline
\end{tabular}


the stable multiregional population in Table 3 . In both cases, California receives approximately 18 percent of the national population with the San Francisco, Los Angeles and San Diego SMSA's receiving 5, 9, and $1 \frac{1}{2}$ percent, respectively. Thus it appears that the spatial allocation effects of proportionally reduced fertility are negligible.

Although the redistributional effects of proportionally reduced fertility are negligible, the age compositional effects are not. As in the single-region model, reduced fertility produces an older population which has a much higher percentage of its members in the 65 years and over age group. However, the interaction of reduced fertility and fixed migration schedules produces an uneven regional allocation of the aged. Thus although California under zero growth would have about 18 percent of its population in the 65 -year and over age group, San Diego would have more (24 percent) while San Francisco would have less (17 percent). The spatial population dynamics leading up to this result are clear. San Diego, because it is a retirement haven, receives relatively "older" jnmigrants than does San Francisco. As the proportion of the aged increases nationally, San Diego will receive a heavier than average net inflow of migrants. This is why its net migration rate changes from a negative 0.4 per 1000 in Table 3 to a positive 4.2 per 1000 in Table 4.. San Francisco's corresponding rates, on the other hand, exhibit a reverse shift, decreasing from a positive net migration rate of 1.2 per 1000 to a negative rate of 0.2 per 1000 .

Finally, Table 4 shows that regions which exhibit higher than average birth rates prior to zero growth will have lower than average birth rates during zero growth. Once again San Diego offers an interesting case study. According to Table 3, it has the highest intrinsic birth rate of all 5 regions in the system (28 per 1000). Yet in Table 4 its intrinsic birth rate is the lowest (12 per 1000). The population dynamics producing this reversal are the same as those outlined 
earlier and result from the relatively older population that San Diego would have under zero growth. (Note that San Diego's intrinsic death rate is the highest both before and during zero growth).

In one of his contributions to the final reports produced by the Commission on Population Growth and the American Future, Peter Morrison (1972, p. 547) observed:

"...demographic processes interact in subtle and often complex ways, and the mechanisms by which declining fertility would influence population redistribution are only partially understood." It is hoped that this paper has identified and illuminated some of these mechanisms. 
Alonso, W. (1973). "Urban Zero Population Growth," Daedalus, CII, 191-206.

Coale, A.J. (1972). "Alternative Paths to a Stationary Population," in Demographic and Social Aspects of Population Growth, Ed., C.F. Westoff and R. Parke, Jr., U.S. Commission on Population Growth and the American Future (Washington, D.C.: U.S. Government Printing office), pp.589-603.

Feeney, G. (1970). "Stable Age by Region Distributions," Demography, VI, 341-348.

Gantmacher, F.R. (1959). The Theory of Matrices, trans, K.A. Hirsch, Vol. 2 (New York: Chelsea Publishing Co.).

Keyfitz, N. (1968). Introduction to the Mathematics of Population, (Reading, Mass.: Addison-Wesley).

(1969). "Age Distribution and the Stable Equivalent," Demography, VI, $261-269$.

LeBras, H. (1971). "Equilibre et Croissance de Populations Soumises a des Migration," Theorecical Population Biology, II, 100-121.

Leslie, P.H. (1945). "On the Use of Matrices in Certain Population Mathematics," Biometrika, XXXIII, 183-212.

Morrison, P.A. (1972). "The Impact of Population Stabilization on Migration and Redistribution," in Population, Distribution, and Policy, Ed., S.M. Mazie, U.S. Commission on Population Growth and the American Future (Washington, D.C.: U.S. Government Printing Office), PP: 543-560.

Parlett, B. (1970). "Ergodic Properties of Population, I: The One Sex Mode1," Theoretical Population Biology, I, 191-207.

Pollard, J.H. (1973). Mathematical Models for the Growth of Human Populations (London: Cambridge University Press).

Rogers, A. (1966). "The Multiregional Matrix Growth Operator and the Stable Interregional Age Structure," Demography, III, 537-544.

(1971). Matrix Methods in Urban and Regional Analysis, (San Francisco, Cal.: Holden-Day).

(1974). "The Multiregional Net Maternity Function and Multiregional Stable Growth," Demography, XI, 473-481.

(1975). Introduction to Mu1tiregional Mathematical Demography

(New York: John Wiley).

Sharpe, F.R. and A.J. Lotka (1911). "A Problem in Age-Distribution," Philosophica1 Magazine, Ser. 6, XXI, 435-438.

Stone, L.O. (1968). "Stable Migration Rates from the Multiregional Growth Matrix Operator," Demography, V, 439-442.

Sykes, Z.M. (1969). "On Discrete Stable Population Theory," Biometrics, XXV, 285-293. 